With bromine, traces were formed in alkaline solution, but none in acid solution. With iodine there was no formation of hydronitric acid in either acid or alkaline solution. The slight tendency of the free halogens to produce hydronitric acid from hydrazine sulphate, consequently decreases with increase of the atomic weight of the halogen.

The maximum yields of hydronitric acid and ammonia obtained in a series of experiments with potassium chlorate, bromate, and iodate, in the presence of sulphuric acid and silver sulphate, were as follows: with potassium chlorate, $\mathrm{I}_{3.32}$ per cent. $\mathrm{HN}_{3}$, I6.96 per cent. $\mathrm{NH}_{3}$; with potassium bromate, II.65 per cent. $\mathrm{HN}_{3}, 27.42$ per cent. $\mathrm{NH}_{3}$; with potassium iodate, $\mathrm{II} .16$ per cent. $\mathrm{HN}_{3}, 16.16$ per cent. $\mathrm{NH}_{3}$. The influence of the silver sulphate in augmenting the yield of hydronitric acid consequently varies directly with the atornic weight of the halogen.

The behavior of a number of other oxidizing agents toward hydrazine sulphate is now under investigation in this laboratory.

CORNELI, ENIVERSITY,

October, rgo7.

\title{
ON THE REACTION BETWEEN LIME AND SULPHUR.
}

BY R. W. THATCHER.

Received August 15, :907.

The compounds which may be formed by the union of calcium and sulphur, either with or without oxygen, are quite numerous and varied in their properties. They have been extensively studied in connection with the theoretical principles involved in the replacement of oxygen by its analogous element sulphur. Recently, the subject has been given a very important economic bearing by the very extensive use of solutions prepared by boiling together in water, lime, sulphur, and sometimes other ingredients, and applied as insecticides for scab on animals and for soft-bodied scale insects on fruit trees. Some idea of the extent to which this wash is being used on the Pacific Coast States may be obtained from the fact that a single firm has recently installed in California a plant which is producing at each single boiling fourteen carloads of a concentrated lime-sulphur solution of twelve times the strength in which it is used in orchard practice, while at least two other firms are manufacturing similar concentrated solutions on a large scale, and a very much larger amount of the wash is produced by home-boiling in orchards and sheep camps.

The formulae which have been used for the preparation of the insecticide wash have differed widely. The various modifications of the original formula have been based on a great variety of conceptions as to the nature of the compounds formed in the wash and their insecticidal properties, none of which, however, were based on any accurate knowl- 
edge of the reactions involved. Because of this, we began in the laboratory, in 1902 , a study of the nature of the reactions involved and the compounds formed when lime, sulphur, and other ingredients, are boiled together in water. This study has been continued, as opportunity has permitted, up to the present time. We have now sufficient data from which to draw certain conclusions, which are presented herewith. Reports of the progress of these investigations have been issued as Bulletins Nos. 56 and 76 of this Station, and complete details of our analytical data up to the date of their issuance may be found therein. The earlier investigations showed clearly that, whereas it had been supposed that the wash was a very complex mixture containing many different compounds, in reality it contains only two characteristic compounds, calciun pentasulphide and calcium thiosulphate, small amounts of sulphite or sulphate being occasionally found as a result of oxidation subsequent to the formation of the true products of the reaction. ${ }^{1}$ Iater, studies were carried on with a view of ascertaining whether the proportion of these two ingredients, or of lime and sulphur in the solution can be varied by changing the conditions of boiling.

The results of the analyses of a few typical solutions, made according to formulae representing the extremes of those which have been suggested for the preparation of the wash, are included in Table I. Nany others, of varying formulae and conditions of boiling, have been prepared and analyzed, but the general relationships found were the same as in those here recorded, and the analytical data are omitted in order to economize

TABLE I.

Compositron of Lime-Sulphur Solutions Prepared According to Different FORMULAS.

Sulphur in roo cc. of solution.

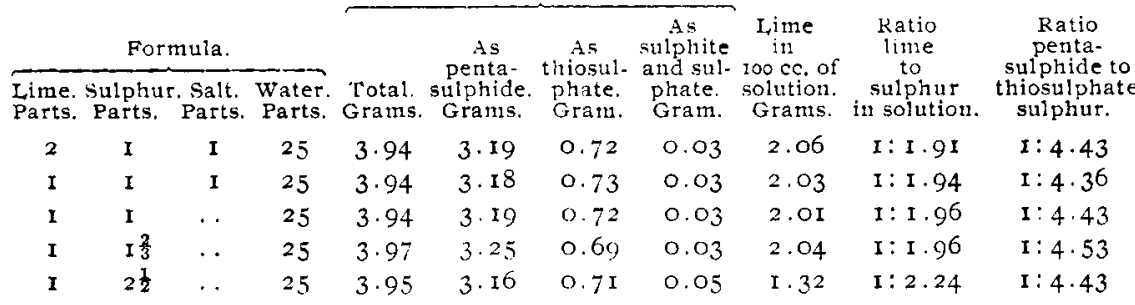

space. Our results show that when freshly slaked lime and sulphur, either with or without the addition of salt, are boiled together in an excess of water, in open vessels, they dissolve in the average proportions of I part calcium oxide to I.94 parts sulphur, if the lime is in excess, and of I part calcium oxide to 2.24 parts sulphur if the latter is present in excess. The solubility of lime, as calcium hydroxide, in water in the

${ }^{1}$ Haywood has independently arrived at similar conclusions, see This Journal, 28. 245, and Bureau of Chem. Bull. No. IOI, 10. 
proportions used, is sufficient to account for nearly two-thirds of the difference between these ratios, and its solubility in the lime-sulphur mixture may be somewhat greater. It is very probable, therefore, that the proportion of calcium in combination with sulphur in the solution is the same regardless of which of the two components is used in excess, the increased amount of lime in solution when the latter is in excess being simply dissolved calcium hydroxide. This excess of calcium hydroxide may after a time unite with some of the calcium pentasulphide of the solution, since if solutions prepared with an excess of lime are allowed to stand for several days, or longer, they frequently deposit bright red or yellow crystals of oxysulphides of calcium. These latter are probably of variable composition, since they have been variously stated to be

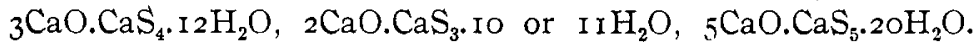
${ }_{4} \mathrm{CaO} \cdot \mathrm{CaS}_{4} \cdot 18 \mathrm{H}_{2} \mathrm{O}$, or ${ }_{3} \mathrm{CaO} . \mathrm{CaS}_{3}$. 14 or $\mathrm{I}_{5} \mathrm{H}_{2} \mathrm{O} \cdot{ }^{1}$

The comparatively slight variations in the proportions of the ingredients found in the several solutions are easily accounted for, either by analytical errors due to the fact that the methods used have been very recently devised and may not be quite perfect, ${ }^{2}$ or by some chemical changes produced by too prolonged boiling of the solutions, resulting in subsequent rearrangements according to reactions which have been pointed out by Haywood. ${ }^{3}$

The possible reactions between calcium hydroxide and sulphur are represented by the following equations:

(I) ${ }_{3} \mathrm{Ca}(\mathrm{OH})_{2}+12 \mathrm{~S}=\mathrm{CaS}_{2} \mathrm{O}_{3}+{ }_{2} \mathrm{CaS}_{5}+{ }_{3} \mathrm{H}_{2} \mathrm{O}$ or $\mathrm{CaO}: \mathrm{S}:: \mathrm{I}: 2.286$

(2) $3 \mathrm{Ca}(\mathrm{OH})_{2}+8 \mathrm{~S}=\mathrm{CaS}_{2} \mathrm{O}_{3}+{ }_{2} \mathrm{CaS}_{3}+{ }_{3} \mathrm{H}_{2} \mathrm{O}$ or $\mathrm{CaO}: \mathrm{S}::$ I: $: 1.524$

(3) ${ }_{3} \mathrm{CaOH}_{2}+{ }_{4} \mathrm{~S}=\mathrm{CaS}_{2} \mathrm{O}_{3}+{ }_{2} \mathrm{CaS}+{ }_{3} \mathrm{H}_{2} \mathrm{O}$ or $\mathrm{CaO}: \mathrm{S}::$ : $: 0.762$

and perhaps intermediate ones, resulting in the formation of $\mathrm{CaS}_{4}$ or $\mathrm{CaS}_{2}$. Schöne states that when calcium sulphide and sulphur are boiled together in water, they invariably dissolve in the proportions to form $\mathrm{CaS}_{4}$ and $\mathrm{CaS}_{5}$. Since our analyses have shown, however, that after allowing for the lime in solution as calcium hydroxide the ratio of lime to sulphur in combination is always about $\mathrm{I}: 2.24$, it appears that equation (I) above represents the reaction by which the chemical union takes place when these two substances are boiled together in water in open vessels. Our results show, furthermore, that any excess of either lime or sulphur above these proportions is left uncombined in the mixture, and has no more insecticidal value than it would have if boiled with water alone. Hence the most economical use of these ingredients for the preparation of lime-sulphur compounds for insecticide purposes re-

'See Watts' Dictionary, Vol. I, 667.

2 The methods used were practically identical with those described by Haywood; This Journal, 28, 247-248, and Bureau of Chem. Bull. No. Ior, 9.

${ }^{3}$ This Journal, 28, 249.

- Pogg. Ann., 117, 58. 
quires that they be taken in the proportions on I part lime to 2.24 parts sulphur. Since in practice, lime is rarely absolutely pure, a somewhat larger proportion of it, say I part to 2 parts sulphur, had best be used. Further, it is sometimes desirable to have an excess of undissolved line in the mixture, as "whitewash" in order to make it more casily visible when sprayed on the tree. In such cases, the lime must be used in larger proportions than I part to 1.94 parts sulphur or none will remain undissolved.

It will be noticed in the above table of analyses that the ratio of sulphur in sulphide form to that in thiosulphate form is always slightly less than would be produced by the reaction represented by equation ( 1 ), i. $\epsilon$. I to 5 . This is undoubtedly due to secondary oxidation of pentasulphide' to thiosulphate during the boiling in open vessels, according to the reaction suggested by Haywood, ${ }^{1}$ since both Haywood's experience and our own have demonstrated that the longer the mixture is boiled after the sulphur is dissolved, the greater the proportion of thiosulphate sulphur becomes. Since the chief, if not the only, insecticidal value of the mixture lies in the pentasulphide sulphur which it contains, care should always be observed in preparing solutions for use as insecticides to prevent this oxidation as far as possible. This can be done by shortening the boiling and by covering the cooking vats so as to exclude the air as nuch as possible.

Concentrated Lime-Sulphur Solutions. - Within the past two years several firms have been experimenting with the view of producing highly concentrated solutions of lime-sulphur compounds to be shipped and sold for insecticide use. A considerable number of these have bcen submitted to us for analysis. Some of the results of these analyses are presented in Table II. In each of the three different brands represented, or solutions manufactured by three different firms (represented by $A$, $B$, and $C$ respectively), the samples which were first produced are recorded first, and the following analyses show the results of later attempts to increase the concentration and proportion of sulphur in solution. These solutions are made by boiling by means of steam heat, a thick "milk of lime" with the proper amount of very finely divided sulphur, in tanks from which the air is excluded as completely as possible by means of heavy wooden covers. The boiling is continued until the maximum amount of sulphur which will stay in solution after cooling is dissolved. The manufacturers state that further concentration of the solutions beyond the point represented by the final sample of each brand results in the separation of crystals on cooling. All these samples have now been standing in our laboratory for six months or more, and show

1 This Journal, 28, 249. 
no deposition of crystals; hence, they probably represent approximately saturated solutions.

\section{TABLE II.}

CoMposition of CONCENTRATEd Lime-SUlphUR SOLUtions.

sulphur in too cc. of solutior.

\begin{tabular}{|c|c|c|c|c|c|c|c|}
\hline $\begin{array}{l}\text { mple } \\
\text { No. }\end{array}$ & $\begin{array}{l}\text { Total. } \\
\text { Grams. }\end{array}$ & $\begin{array}{c}\text { As } \\
\text { penta- } \\
\text { sulphide. } \\
\text { Grams. }\end{array}$ & $\begin{array}{c}\text { As } \\
\text { thio- } \\
\text { sulphate. } \\
\text { Grams. }\end{array}$ & $\begin{array}{l}\text { As } \\
\text { sulphite } \\
\text { and } \\
\text { sulphate. } \\
\text { Gram. }\end{array}$ & $\begin{array}{l}\text { Lime in } \\
\text { I00 cc. } \\
\text { of } \\
\text { solution. } \\
\text { Grams. }\end{array}$ & $\begin{array}{l}\text { Ratio } \\
\text { limie } \\
\text { to } \\
\text { sulphut } \\
\text { in solution. }\end{array}$ & $\begin{array}{c}\text { Ratio } \\
\text { pentasulphide } \\
\text { to } \\
\text { thiosulphate } \\
\text { sulphur. }\end{array}$ \\
\hline$A_{1}$ & 20.30 & 17.68 & 2.05 & 0.57 & 8.17 & I: 2.48 & $\mathrm{I}: 8.62$ \\
\hline$A_{2}$ & $32 \cdot 38$ & 29.79 & 2.02 & 0.57 & 12.49 & $1: 2.72$ & $I: 14.75$ \\
\hline$A_{3}$ & 35.63 & 34.18 & I. 23 & 0.22 & I 3.74 & I: 2.49 & I: $27 \cdot 78$ \\
\hline $\mathrm{B}_{1}$ & 23.64 & 19.00 & 4.10 & 0.54 & 10.50 & $1: 2.29$ & I: 4.63 \\
\hline $\mathrm{B}_{2}$ & $25 \cdot 47$ & $22 \cdot 5^{8}$ & 2.08 & $0.8 \mathrm{I}$ & 10.66 & $1: 2.39$ & $I: 10.85$ \\
\hline $\mathrm{B}_{3}$ & $30.2 I$ & 27.80 & I. 74 & 0.67 & II. 54 & $1: 2.61$ & $I: 15.92$ \\
\hline $\mathrm{B}_{4}$ & 35.89 & 34.29 & I. 48 & 0.12 & I 4.28 & $1: 2.52$ & $I: 23.18$ \\
\hline$C_{1}$ & 17.65 & 14.00 & $3 \cdot 32$ & 0.33 & 8.67 & $1: 2.04$ & $I: 4.19$ \\
\hline $\mathrm{C}_{2}$ & 26.98 & 24.82 & I. 88 & 0.28 & 10. 47 & $1: 2.5^{8}$ & $I: 13.20$ \\
\hline $\mathrm{C}_{3}$ & 34.07 & 32.03 & I. 80 & 0.24 & $13 \cdot 30$ & $1: 2 \cdot 5^{6}$ & $I: 17.78$ \\
\hline
\end{tabular}

It will at once be noticed from these results that in the highly concentrated solutions the proportion of sulphur in sulphide form is very largely increased over that formed in the solutions prepared in open vessels, as shown in Table I. It is a well-established principle that the pentasulphide is the highest possible polysulphide, and the reaction by which calcium pentasulphide is produced by the union of lime and sulphur (see Equation I above) yields only 80 per cent. of the total sulphur in sulphide form, whereas in solutions $A_{3}, B_{4}$, and $C_{3}$, the proportion of the total sulphur which is in this form is 95.95 per cent., 95.54 per cent. and 94.00 per cent. respectively. Hence in the preparation of these solutions some secondary reaction must take place, resulting in the change of a large part of the thiosulphate into polysulphide sulphur. Just what this secondary reaction may be is very difficult to determine. The following possible equations have suggested themselves:

$$
\text { (5) } \begin{gathered}
\mathrm{CaS}_{2} \mathrm{O}_{3}+\mathrm{Ca}(\mathrm{OH})_{2}+{ }_{4} \mathrm{~S}=\mathrm{CaS}_{5}+\mathrm{CaSO}_{4}+\mathrm{H}_{2} \mathrm{O} \\
\text { (6) } \mathrm{CaS}_{2} \mathrm{O}_{3}+3 \mathrm{Ca}(\mathrm{SH})_{2}={ }_{2} \mathrm{CaS}_{5}+{ }_{3} \mathrm{Ca}(\mathrm{OH})_{2} \\
\text { (7) } \mathrm{CaS}_{2} \mathrm{O}_{3}+{ }_{3} \mathrm{H}_{2} \mathrm{~S}=\mathrm{CaS}_{5}+3 \mathrm{H}_{2} \mathrm{O} \\
\text { (8) }{ }_{4} \mathrm{CaS}_{2} \mathrm{O}_{3}=\mathrm{CaS}_{6}+{ }_{3} \mathrm{CaSO}_{4} .
\end{gathered}
$$

A reaction according to (8) appears to be very improbable, both from theoretical reasons and from the fact that it would produce much more calcium sulphate than we have ever found in such a mixture. A reaction according to $(7)$ or (6) requires the previous formation of hydrogen sulphide or calcium sulphhydrate respectively, the production of either of which under the conditions of boiling these solutions seems highly improbable. Equation (5) seems, therefore, to represent the most probable reaction of those which have suggested themselves. The presence 
of a larger proportion of sulphate sulphur in these concentrated solutions than was found in the dilute solutions boiled in open air also favors the supposition that the reaction by which pentasulphide is produced at the expense of thiosulphate is accompanied by the formation of calcium sulphate. The smaller proportion of sulphate sulphur in some of the more concentrated solutions seems to oppose this view, however. On the other hand, the analytical methods for distinguishing quantitatively between these several forms of sulphur compounds are not yet thoroughly perfected and it may be that this apparent objection to the reaction would be removed if more exact methods of analysis were available. In the absence of better analytical methods, these results are presented as the best obtainable, and the conclusions suggested as a possible step toward a better knowledge of the reactions between lime and sulphur under varying conditions.

I.AIBORATORY OF THE

WASHIN 3 TON AGRICLLTURAL EXPERIMENT STATION, PELEMAN, WaSH.

[CONtribution from the Havemeyer Chemical Laboratory, New York UniverSITY.]

\section{THE RELATIVE SOLUBILITY OF THE SILVER HALIDES AND SILVER SULPHOCYANATE.}

IBY ARTHUK E. HILL.

Received October 22, 1907.

The theory of electrolytic dissociation teaches that if saturated solutions of two very insoluble salts which have an ion in common could be mixed without increase of volume, precipitation of both salts would occur. For example, saturated solutions of $\mathrm{AgCNS}$ and $\mathrm{AgCl}$ would, upon mixing, precipitate both compounds in part, since by the addition of silver ion the solubility product of each salt would be exceeded. The quantities of chloride and sulphocyanate precipitated would be such as to leave the solution saturated in respect to both salts, and the equilibrium finally reached would be expressed for the respective compounds by the equations $\mathrm{C}_{\mathrm{Ag}} \times \mathrm{C}_{\overline{\mathrm{CNS}}}=\mathrm{K}_{1}$ and $\mathrm{C}_{\mathrm{Ag}} \times \mathrm{C}_{\overline{\mathrm{Cl}}}^{-}=\mathrm{K}_{2}$, where $\mathrm{C}$ stands for concentration in equivalents per unit volume, $\mathrm{K}_{1}$ and $\mathrm{K}_{2}$ are the products of the free ions (solubility products), and the subscripts denote the respective ions. By division,

$$
\frac{\mathrm{C}_{\mathrm{Ag}}^{+} \times \mathrm{C}_{\mathrm{CNS}}^{-}}{\mathrm{C}_{\mathrm{Ag}}^{+} \times \mathrm{C}_{\mathrm{Cl}}^{-}}=\frac{\mathrm{K}_{1}}{\mathrm{~K}_{2}} \quad \text { (Equation I) }
$$

The common term $\mathrm{C}_{\mathrm{Ag}}$ may be cancelled out, the relation becoming

$$
\overline{\mathrm{C}_{\mathrm{CN}}^{-}}=\frac{\mathrm{K}_{1}}{\mathrm{~K}_{2}} \quad \text { (Equation 2) }
$$

